\title{
The Influence of Ultraviolet Radiation on Eye
}

\author{
Lepša Žorić ${ }^{1 *}$ and Milan Stojčić ${ }^{2}$ \\ ${ }^{1}$ Faculty of Medicine, University of Priština, Kosovska Mitrovica, Serbia \\ ${ }^{2}$ Railway Health Institute, Ophthalmology Depertment, Belgrade, Serbia
}

\section{Abstract}

Ultraviolet radiation has influence on some ophthalmological diseases pathogenesis.

In the text described are form of light which can be causative for eye diseases and they are listed.

Recomendations for protection are also mentioned.

Keywords: UV Radiation; HEV radiation; Cataract; AMD; Pterygium; Uveal melanoma

The Sun, like oxygen, is a requirement for life on Earth. The man is a daily organism and in his activities follows a circadian rhythm. Sunlight is necessary for a complete physical and mental development of human being.

The human eye is exposed to sunlight for decades. However, the full spectrum of solar radiation has wavelengths with considerable damaging potential. Photooxidative stress is primarily caused by the absorption of light by the organic molecules [1,2]. The absorption of electromagnetic radiation of a tissue depends on the excitability of its molecules. Low-energy photons in interaction with electrons in organic molecules produce a higher energy level in the outer electrons orbitals. Resulting excited states allow formation of reactive oxygen radicals. The action spectrum is a measure of the biological effects of light as a function of its wavelength. It depends on the number of photons absorbed by chromophores - pigments or other molucelus which are needed to start up the process. Photodynamic effect is defined as the damaging effects of light, oxygen and sensitizing components. The action spectrum needed for.the human lens opacification, for example, has a maximum at a wavelength of $300 \mathrm{\eta m}$, which corresponds to the ultraviolet part of the spectrum (UVB rays).

UVC rays have wavelengths $100-280 \mathrm{\eta m}$. These rays are with the highest energy and dangerous damaging potential for eye. The atmospheric ozone layer blocks virtually all UVC rays. However, ozone depletion,-ozone holes, can allow penetration of UVC rays to the earth's surface and cause serious health problems.

UVB rays (280-315 $\eta \mathrm{m})$ have less damaging potential. They are partially filtered by the ozone layer and the part reaches to the ground. In small doses cause darkening of the skin (suntan). Higher doses and/ or longer exposures have cumulative impacts and can result burns and degenerative changes of the skin and eye. The eye cornea absorbs wavelengths up to $295 \eta \mathrm{m}$. UVA - 315-400 $\eta \mathrm{m}$ reach the ground: and have a role in the development of certain types of cataracts. HEV is a high-energy visible radiation - 400-500 $\mathrm{\eta m}$. This is a blue part of the spectrum and it is involved in the pathogenesis of Age-Related Maculopathy (AMD). The wavelengths of the visible part of the spectrum showed toxicity in tissue cultures to which was added a photosensitizer (eg psoralen).

The intensity of UV rays on an organism depends on: latitude (the strongest in the areas around the earth's equator), altitude (at higher altitudes the thinner atmosphere), time of the day (10-14 hours), reflection from the-ground, the position and intensity of ozone damage, location (city, forest, open space) and drugs which can increase photosenzibilty (tetracycline, birth control pills, diuretics, tranquilizers, sulfonamides).
We have a series of experimental evidence that UVB rays cause cataracts [3,4]. There are limited evidence that UVB rays causes cortical and posterior subcapsular cataracts (epidemiology, population studies) and no evidence that UVB rays cause nuclear cataracts. Other risk factors are aging, sex, race, genetic factors, environmental factors, inflammation and lifestyle habits- smoking, alcohol intake and nutrition.

Pterygium is a duplication of conjunctiva, located on the nasal side of bulbar conjunctiva. Histologicaly it is presented as actinic elastosis and fibrovascular proliferation. The genesis is fairly known, but ultraviolet exposure has an influence [5].

Pinguecula is hyaloid degeneration of conjunctival connective tissue, seen in elderly. Pinguecula has a form of a small whitish-yellowish node. It also has a nasal localization and secondary changes, like calcifications are common. Scleral plaque belongs to older population, as well. Commonly is situated just in front of the medial and lateral recti. Presentation is in form of ilateral, symmetric, sharply demarcated vertically ovoid, or sometimes rectangular zones of increased scleral translucency. UV radiation plays a role in their patogensis [6].

Photokeratiitis is also known as actinic (solar) keratitis, or snow blindness. Photokeratitis appears after latency period of several hours and has acute course. Besides activities on mountains without protection, it can be caused with UV lamps and gas welding.

UV radiation can be one of causative factors for uveal malignant melanoma [7]. In this context, it is interesting that welding is a more significant risk factor then ambiental UV radiation. Arc welding produces the full spectrum of UV radiation and in a short distance from worker, hence it has high damaging potential.

Other ophthalmologic diseases in which pathogenesis UV radiation participates are climatic keratopathy [8] and eyelid tumors.

Age-related macular degeneration (AMD) is one of leading causes of legal blindness. HEV radiation can participate in AMD formation [9]. Persons without lens (non phakik) and with clear artificial lenses

*Corresponding author: Lepša Žorić, Faculty of Medicine, UPKM, Anr Dinana bb, 38200 Kosovska, Mitrovica, Serbia, Tel: +381 63 8654938; E-mail: lepsaz@eunet.rs

Received March 23, 2013; Accepted April 16, 2013; Published April 28, 2013

Citation: Žorić L, Stojčić M (2013) The Influence of Ultraviolet Radiation on Eye. Primary Health Care 3: 133. doi:10.4172/2167-1079.1000133

Copyright: () 2013 Žorić L, et al. This is an open-access article distributed under the terms of the Creative Commons Attribution License, which permits unrestricted use, distribution, and reproduction in any medium, provided the original author and source are credited. 
implanted are at particular risk, because UV rays whivh are normaly absorbed by lens, now can reach their retina. However, the other risk factors play important role in this disease genesis.

UV radiation is a risk factor for numerous eye diseases and, unlike genetics, sex, age of life or race, can be considered as the preventable one. Eye protective lenses are recommended whenever the sun comes out and they need to completely block UV rays and protect from blue light. Corrective lenses and Intraocular Implants (IOL) are produced with filters. Wide brim hats and caps are protecting to some extent. Protection at work and in sports is equally, if not more important.

Children spend more time outdoors than adults. It is estimated that about half of UV rays receive up to 18 years of age. The eye lens in childhood has a small ability to absorb UV rays and allows greater penetration to the deeper eye structures, including retina [10]. Eye protection is important in childhood, as well, because almost all mentioned diseases appear in older age and we do not know the exact time of their evolution.

In the recommendations for limiting exposure to UV rays we must be careful. Finally and again we are daily organisms. Without sunlight is not possible visual functions development. Small amounts of UV are beneficial for people and essential in the production of vitamin $\mathrm{D}$ [11]. UV radiation is also used to treat several diseases, including rickets, psoriasis, eczema and jaundice.

\section{References}

1. Pandey R, Mehrotra S, Ray RS, Joshi PC, Hans RK (2002) Evaluation of UVradiation induced singlet oxygen generation potential of selected drugs. Drug Chem Toxicol 25: 215-225.

2. Fact sheet $\mathrm{N}^{\circ} 305$, December 2009. Ultraviolet radiation and human health.

3. Okuno T, Nakanishi-Ueda T, Ueda T, Yasuhara H, Koide R (2012) Ultraviolet action spectrum for cell killing of primary porcine lens epithelial cells. J Occup Health 54: 181-186.

4. McCarty CA, Taylor HR (2002) A review of the epidemiologic evidence linking ultraviolet radiation and cataracts. Dev Ophthalmol 35: 21-31.

5. Sekelj S, Dekaris I, Kondza-Krstonijević E, Gabrić N, Predović J, et al. (2007) Ultraviolet light and pterygium. Coll Antropol 1: 45-47.

6. Loeffler KU, Sastry SM, McLean IW (2001) Is age-related macular degeneration associated with pinguecula or scleral plaque formation? Curr Eye Res 23: 3337.

7. Shah CP, Weis E, Lajous M, Shields JA, Shields CL (2005) Intermittent and chronic ultraviolet light exposure and uveal melanoma: a meta-analysis. Ophthalmology 112: 1599-1607.

8. Podskochy A, Fagerholm P (2001) Repeated UVR exposures cause keratocyte resistance to apoptosis and hyaluronan accumulation in the rabbit cornea. Acta Ophthalmol Scand 79: 603-608.

9. Algvere PV, Marshall J, Seregard S (2006) Age-related maculopathy and the impact of blue light hazard. Acta Ophthalmol Scand 84: 4-15.

10. Lakkis C, Weidemann K (2006) Evaluation of the performance of photochromic spectacle lenses in children and adolescents aged 10 to 15 years. Clin Exp Optom 89: 246-252.

11. Lucas RM, Repacholi MH, McMichael AJ (2006) Is the current public health message on UV exposure correct? Bull World Health Organ 84: 485-491. 